\title{
Preschool children's understanding of racial cues in drawings and photographs ${ }^{\text {25 }}$
}

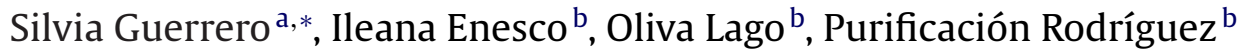 \\ a Universidad de Castilla-La Mancha, Developmental Psychology, Av. de los Alfares, \\ 42, E.U. Magisterio Fray Luis de Leon, 16071 Cuenca, Spain \\ b Universidad Complutense de Madrid, Campus de Somosaguas 28223, Pozuelo de Alarcón, Madrid, Spain
}

\section{A R T I C L E I N F}

\section{Keywords:}

Young children

Racial awareness

Social categorization

\begin{abstract}
A B S T R A C T
Studies of the development of racial awareness have used - albeit asystematically - stimuli of varying degrees of realism (dolls, drawings, photographs). Although researchers have weighed the advantages and disadvantages of using one or the other type of material with young children, there are no empirical studies that determine whether the nature of the material affects responses. We examined whether the use of drawings or photos affected children's responses when assessing diverse components of racial awareness. Ninety preschoolers from the majority group in Madrid, Spain, were divided into four groups by age and condition (drawing vs. photo). Children performed person description, social categorization, preference, and matching tasks. Type of material affected performance, although this influence varied by age and task type.
\end{abstract}

(c) 2009 Elsevier Inc. All rights reserved.

Developmental research has revealed children's early ability to organize people into categories according to gender, age, skin color and body size (Cramer \& Steinwert, 1998; Madey \& Ondrus, 1999; Powlishta, Serbin, Doyle, \& White, 1994). The basic components of racial awareness and early racial attitudes have been observed to develop as early as preschool (Aboud, 1988). Although findings vary, some studies report that children are capable of differentiating and labeling racial groups at about 3 years of age (Katz \& Kofkin, 1997; Nesdale, 2002), correctly identifying with their own group (Clark \& Clark, 1947; Marsh, 1970) and displaying favoritism for it (Aboud, 1987, 1988; Doyle \& Aboud, 1995; Rutland, Cameron, Bennett, \& Ferrell, 2005). Other studies, however, have found no sign of these skills

\footnotetext{
if This work was supported by a grant to the second author the Spanish Ministry of Education and Science of Spain (SEJ-200612642) and by a research grant to the first author from the Community of Madrid (FPI), Spain.

* Corresponding author. Tel.: +34 969179170.

E-mail address: silvia.guerrero@uclm.es (S. Guerrero).
} 
until at least one year later (Aboud \& Amato, 2001), and even later if the material the children dealt with were groups other than "black" and "white" (Aboud, 1988; Davey, 1983; Enesco, Navarro, Giménez, \& del Olmo, 1999; Guerrero \& Enesco, 2008; Williams \& Morland, 1976). Some studies with preschool children find that in person-categorization tasks children are guided more by racial cues than by gender (Ramsey, 1991; Ramsey \& Myers, 1990), whereas other studies find the opposite (Van Parys, 1981). A contributor to these discrepancies may be sociodemographic standing (socioeconomic status, nationality, or ethnicity), although many of the aforementioned studies involved relatively comparable groups

Since the appearance of the first studies of the development of racial awareness, research has advanced considerably in the design of new measures. Assessment procedures (e.g., forced-choice vs. open questions) have also varied and can affect children's responses. Minor changes in the item content (Who would you like to play with? vs. Who would you like to sit next to in class?) can modify the target of the child's attention, placing more focus on gender or on race. The forced-choice procedure can lead to misinterpretation and to response by elimination rather than by choice. These seemingly minor differences can lead to misinterpretation of the results if not addressed (Aboud, 1988; Davey, 1983; Ramsey \& Myers, 1990; Semaj, 1981). Other features may cause similar variation. For example, the presentation of just two stimuli - black and white - may cause similar problems to those of forced-choice, favoring response by elimination. Additionally, repetition of the same set of stimuli in successive questions can lead to contamination as the test proceeds. These variables have not been systematically controlled and, at the present time, we have only some intuition as to how they may affect children's responses.

In the present study, we address another such variable, the type of material presented to children to assess their racial awareness. Previous research has been conducted using mainly three types of stimuli - dolls, drawings, and photographs - that represent people from different racial groups. Despite some discussion of the advantages and disadvantages of working with certain kinds of material, there have been no controlled studies that have assessed their influence on children's responses, especially from a developmental viewpoint in preschool children. In fact, many studies include children from 3 to 5 years of age in the same group, ignoring the cognitive and emotional differences that are typical across this age range. As noted by Milner (1983), the investigator infers that "children react to these figures [dolls and pictures] as if they were real people and in this way demonstrate their feelings towards the groups that the figures represent" (p. 107). Aboud (1988) suggests that "although the results with young children using dolls seem to be comparable to those found using pictures, more appropriate comparisons can be made with children over 6 years if all studies use the pictures format" (p. 63) (see also Enesco, del Olmo, Giménez, \& Paradela, 1998). Even if children are dealing with more realistic stimuli, such as photos, it is difficult to know whether they are acting as if the photo is a member of the reference group or a particular case. They may be responding to the doll or drawing itself and not to the more abstract categories of men and women or black and white (Madole \& Oakes, 1999). Hence, there is a need for developmental studies that assess the efficacy of the diverse materials to measure racial awareness in small children.

It is surprising that this issue has received so little empirical attention given that numerous developmental studies in other areas have revealed that until the age of 3-4 years, children do not consider different types of stimuli (photos, drawings, or three-dimensional objects) that represent the same referent to be comparable (Callaghan, 1999, 2000; Callaghan \& Rankin, 2002; DeLoache, 1987, 2000, 2002; Rakoczy, Tomasello, \& Striano, 2005). In some clinically oriented work, differences due to the material were found in children's responses. MacDonald, Kirkpatrick, and Sullivan (1996) presented photographs and drawings of faces that expressed different emotions to 3-6-year olds. They found that the children recognized the emotions better in the drawings than in the photographs. According to these authors, it may be that photographs hinder children's comprehension and interpretation because their attention is drawn to the greater quantity of details provided by the photo in contrast to the drawings (see also Cunningham \& Odom, 1986). The authors also reflect on the therapeutic consequences of working with more or less realistic stimuli, underscoring that in children who have suffered abuse, the more realistic formats (photographs) may provoke high levels of anxiety but the less realistic stimuli (dolls) may not adequately evoke the referent (Sullivan, Kirkpatrick, \& MacDonald, 1995). The debate continues regarding the influence of the material on young children's performance. 
The present study investigates whether the use of different types of material affects preschool children's performance in racial awareness tasks. Although there is no previous systematic works in this field that allows us to formulate specific hypotheses, we predict that the type of material will affect young children's responses, consistent with findings of such effects in other kinds of tasks. Specifically, we assume that due to their realistic nature photographs will draw more attention to racial cues than drawings. Additionally, we assume that influence of the material will be affected by the type of task and by children's age. With regard to type of task, we expect that photographs will trigger more racial-biased responses in the socio-affective task (i.e., preferences) than in the sociocognitive tasks (i.e., person categorization). With regard to age, children younger than four years of age will be less affected by type of material than older children, considering previous studies showing little sensitivity to racial cues in children aged 3 to 4 years (Giménez \& Harris, 2002; Guerrero \& Enesco, 2008).

We studied preschool children between 3 and 6 years of age. All performed the same tasks (person description, person categorization, racial labeling, preference, and matching), but with different material-either drawings or photographs depicting white and black children. To justify the choice of these targets, it is necessary to provide some data on immigration in Spain and its socio-historical context, which is very different from countries like the USA.

Spain began to receive immigrants in the 1980s and since then, the immigrant population has risen from $0.5 \%$ to $13 \%$ of the total Spanish population. In cities like Madrid it has risen to $17 \%$ (INE, 2008). The vast majority of immigrants are of low-socioeconomic status. Although explicit inter-ethnic conflicts in Spain are not common, racial segregation is a growing problem in Spanish society at various levels, including education, work and health services. Teachers usually report more segregation and intergroup conflicts at school among older than among younger children.

The percentage of black Africans in Spain (about 4\% of the total population) is considerably lower than that of other minorities such as Latin Americans (37\%, INE, 2008). Nonetheless, blacks have been and remain the prototype of racial out-group for Spanish children. In a recent study with 3-6-year olds in which three targets were presented (whites, blacks and Latin Americans), children's responses focused on whites and blacks, while Latinos were virtually ignored (Guerrero, Enesco, \& Lam, 2009). Moreover, in line with this result, the term 'black' was the only label that children understood. Therefore, to test the influence of type of material, we selected this category as one we knew would be meaningful to children.

\section{Method}

\subsection{Participants}

A total of 90 Spanish preschool children (44 boys) from the majority group (white children) participated in the study, aged between 36 and 73 months ( $M=54$ months). They were enrolled in various public schools of the Autonomous Region of Madrid. The schools had a heterogeneous ethnic structure and were located in low-SES residential areas. The percentage of immigrants in the schools was $25 \%$, distributed as follows: $12 \%$ Latin American, 5\% Asian, 3\% northern African, 3\% non-EU European, and $2 \%$ black African children.

Participants were distributed into four groups, based on age and assignment to condition. The two conditions were the drawing condition (DC) and the photo condition (PC). In the DC, there were 22 children between 38 and 53 months ( $M=44$ months) and 21 children between 54 and 71 months ( $M=60$ months); in the PC, there were 26 children between 36 and 53 months ( $M=47$ months) and 21 children between 55 and 73 months ( $M=68$ months).

\subsection{Materials}

As the main goal of the study was to determine the extent to which the nature of the material used to represent people from different racial groups affects children's responses, we created equivalent photographic and pictographic material. 


\subsubsection{Photographic material}

Eight $10 \mathrm{~cm} \times 8 \mathrm{~cm}$ photographs were chosen that differed by: (a) gender ( 4 boys and 4 girls); (b) physical traits linked to race ( 4 photos of black children and 4 photos of white children), such as color of skin, type of hair, the nose, and the mouth; and c) the color of their clothing ( 4 dressed in blue and 4 in orange), as a control variable. We included this last characteristic to assess the relative salience of the two social categories (gender and race) with respect to a non-social category (color of clothes). The photographs were selected from a set of photos that had previously been taken of children (with parental permission) aged between 7 and 8 years, enrolled in multi-ethnic schools in Madrid. To select the specific photographs used in this research, a questionnaire was administered to 208 university psychology students. They responded to various questions about the photos: First, they identified the racial group for each photo; then, they rated on a Likert scale degree of representativeness and attractiveness (To what extent you think this photo is a good example of his/her racial group; How attractive is this person for you, regarding his/her racial group?). We selected the photos that had a reasonable degree of representativeness and attractiveness.

\subsubsection{Pictographic material}

This material was made up of 8 drawings $(12 \mathrm{~cm} \times 4 \mathrm{~cm})$ that varied on the same aspects as the photographic material (gender, color of skin, and color of clothing). To preserve the racial differences in facial features, the drawings were made from previously scanned photos of black and white children aged between 7 and 8 years, using the MAC Drawing Software Program: Thus, the drawings maintained not only the color of skin but also the facial features of each racial group, including the width of the nose, the shape of the lips and the texture of hair.

\subsection{Design and procedure}

Prior to the implementation of the study, the children, their parents, and the School Council were asked to participate in the research. Several trained research assistants individually interviewed the children for about $20 \mathrm{~min}$ in a quiet room at their school. The interviews were audiotaped and transcribed.

We administered a semi-structured interview, assessing various components of children's racial awareness: (a) perception of similarities and differences between different racial groups - Black and White - (person description, person categorization, drawing-photograph matching), (b) comprehension of the conventional racial categories (race labeling), and (c) early preference biases toward the in-group. Task instructions and order of presentation were the same for all participants. The interview started with the person-description task, followed by person categorization and race labeling. The two final tasks were preferences and matching.

\subsubsection{Task 1: person description}

To investigate whether children spontaneously used more racial cues to describe people when using certain material, they were asked to look at two stimuli (a white boy and a black girl), one by one, and to describe the target in each one: What do you see here? What is ... like? Tell me everything that you see here. For half of the participants in each group, the order of presentation was white boy-black girl. For the remainder, it was the reverse (black girl-white boy). Thus, the task consisted of two trials, one for the black figure, and one for the white figure. The responses were classified into the following four categories (not mutually exclusive), used in a previous study (Guerrero \& Enesco, 2008): gender, physical non-racial cues (i.e., hairstyle), color of clothes, and color of skin. This last category included both conventional racial labels (i.e., Black, White) and idiosyncratic words that children used to refer to the targets' skin color (e.g., pink, light brown and dark brown). In such cases, the interviewer followed up with probes to be sure that the participant was referring to the skin color and not to other non-racial features.

Independent inter-coder agreement for $15 \%$ of the interviews was consistently over $95 \%$. Any disagreement between coders was discussed until a consensus was reached. There were no disagreements about the coding of the social categories (race and gender). 


\subsubsection{Task 2: person categorization}

In this task, children had to spontaneously classify the eight stimuli (photographs or drawings), creating as many groups as they wished. Our goal was to determine whether the children used racial criteria more frequently to guide their classifications with certain materials. The stimuli were spread out before the child. The instruction was: Put in one pile the ones that go together. All responses were coded in five categories: gender, color of clothes, skin color, mixed criteria (for example, making four different groups by combining gender and color of clothes), and no criteria.

\subsubsection{Task 3: race labeling}

The same material presented in the previous tasks was used to evaluate children's knowledge of conventional labels employed to name the target groups (Black and White). Here, our goal was to determine whether the children recognized racial labels more easily when using certain materials (photos or drawings). The eight stimuli were spread out on the table and two boxes were placed in front of the child. The instruction explicitly mentioned the racial labels: Put the white ones in one box and the black ones in the other box. For purposes of analysis, the children's classifications were categorized as correct (1) or incorrect (0) responses. Only a complete classification by race (the 4 Blacks and the 4 Whites in different boxes) was considered a correct response.

\subsubsection{Task 4: preference}

This measure of social affect assessed children's preferences for the targets. The goal was to examine whether the intensity of in-group preferences differed by condition. Once again, the eight stimuli (photographs or drawings) were spread out on the table and the child had to choose one of them. The instruction was: Which one do you like the most?

All the above tasks have been used in numerous prior studies. Nevertheless, it is important to note that in previous research on racial preferences, the most common strategy has been to employ a much smaller number of stimuli, usually between 2 and 3 figures of different racial groups (i.e., one White and one Black, or one White, one Black, and one Asian). In this study, we extended the number of stimuli to 8, with 4 figures of each racial group (Black and White), to reduce the risk of the children choosing by elimination. Note that even though the proportion of members of each racial category was the same within each category, the members also varied in gender and color of clothes.

\subsubsection{Task 5: drawing-photograph matching}

This task was designed to investigate whether children are able to identify a social category (race and gender) beyond peripheral cues (such as color of clothes). The task included two trials. In the first one, the drawing of the White boy in blue was presented. At the same time, four photographs were displayed: Black boy in blue, White boy in orange, White girl in orange and Black girl in blue. The instruction was: Someone has made a drawing (pointing to the drawing) of one of these children in the photos. Who is the child...? In the second trial, all the stimuli were the same as in the first trial, except that the drawing presented was a Black girl in orange. For a correct response, children had to avoid peripheral cues, such as the color of clothes (note that the color of the shirt never coincided in the correct matches), and focus on social categories (gender and race). Responses were coded from to 0 to 2 , depending on whether they had correctly matched none (0), one (1), or two (2) figures.

In contrast to the rest of the tasks of the study, which were based on classic tests, the matching task is novel; in the review of prior research we found no similar tests. It is the only task to our knowledge in which children are explicitly requested to compare stimuli having two different formats but with a common referent. To be able to perform this match correctly, as there were distracters (color of the shirt), the child is assumed to understand that both stimuli, photo and drawing, have a common referent, keeping constant both the gender and the color of skin. In comparing performance across conditions, our interest was to establish whether the use of one or another type of material (photos or drawings) facilitated correct responses in this task. 
Table 1

Percentage of responses guided by racial cues, by condition and age group.

\begin{tabular}{llllll}
\hline & \multicolumn{2}{l}{ Drawing $(\mathrm{DC})$} & & \multicolumn{2}{l}{ Photographs (PC) } \\
\cline { 2 - 3 } \cline { 5 - 6 } & Younger $(n=22)$ & Older $(n=21)$ & & Younger $(n=26)$ & Older $(n=21)$ \\
\hline Person description & 18.2 & 81 & 53.8 & 71.4 \\
Person categorization & 13.6 & 33.3 & 90.5 & 50 & 5 \\
Race labeling & 45.5 & 66.7 & 73.1 & 75 \\
Preferences & 68.2 & 28.6 & 36 & 90.5 \\
Matching (2 trials) & 13.6 & & & 47.6 \\
\hline
\end{tabular}

\section{Results}

A check for gender differences in each of the tasks was performed, and no significant differences were found in any of the comparisons. Consequently, genders were pooled in all analyses.

\subsection{Task 1: person description}

In this task, all responses were coded (up to a maximum of five responses for each stimulus presented). With one exception, all participants gave at least one codable descriptor for each stimulus presented. In general, older children provided more codable descriptors than younger children (a mean of 3.1 vs. 2.3 descriptors for each stimulus). By condition, means for the older children were 3.6 and 2.7, for DC and PC, respectively; for the younger ones they were 2.5 and 2.1, for DC and PC, respectively.

The first label used by the children to describe each figure was analyzed. The most frequently used dimension, in both DC and PC groups, was gender (93\% and 83\%, respectively). No participant mentioned race of the figures first.

PC participants mentioned racial traits more frequently in their descriptions (61.7\%) than did DC participants (48.8\%), although this difference was not statistically significant. As seen in Table 1, older children were more likely to refer to the figures' racial attributes than were younger children, $\chi^{2}(1$, $n=90)=13.58, p<.001$, whether the material presented was a photo or a drawing. (It should be noted, however, that older children's use of on average almost one more descriptor than younger children gave them a somewhat greater chance of doing so.) The influence of material was significant only for the younger children: PC participants were significantly more likely to refer to skin color than were DC participants, $\chi^{2}(1, n=48)=6.47, p=.011$.

In this task, all participants had to describe two stimuli of different racial groups (Black and White), but the presentation order of the stimuli was counterbalanced: Both in DC and in PC, half of the participants began their description with a Black figure and the other half with a White figure. The results showed a significant effect of presentation order. Starting with the Black figure instead of the White one increased the probability of using racial terms in the description of both figures $(68.2 \%$ vs. $43.5 \%), \chi^{2}(1, n=90)=5.56, p=.018$. However, analyzing each condition (PC and DC) separately, effect of presentation order only reached statistical significance in the picture condition: Again, the children who began with the photo of the Black child mentioned skin color in their descriptions of both photographs more frequently $(77.3 \%)$ than did children who began with the photo of the White child (48\%), $\chi^{2}(1, n=47)=4.24, p=.039$.

Gender was used by practically all participants, both in DC (100\%) and PC (91.5\%) conditions, which shows that this social category was more relevant than race for our participants. Another noteworthy result was the high percentage of references to non-racial physical traits, such as hairstyle (87.5\%), which exceeded references to skin color (55.3\%). There were also numerous descriptions that referred to a socially irrelevant variable such as color of clothes (54.4\%).

\subsection{Task 2: person categorization}

The two most frequent dimensions children used to organize the figures in this task were gender (32.3\%) and color of clothes (26.7\%). Very few children spontaneously sorted the figures according to 
skin color-14 of 90 , or $15.6 \%$. The second row in Table 1 shows the percentage of children that divided the material dichotomously into Black-White figures, or that formed various pairs using race along with another variable (i.e., four pairs that coincided in skin color and gender or in skin color and color of clothes).

Despite the scarce percentage of categorizations based on skin color, attention to this trait was related to type of material and age. Thus, drawings favored skin-color classification (23.3\%) more than photographs (8.5\%), a difference that was marginally significant, $\chi^{2}(1, n=89)=3.55, p=.059$. For older children, drawings facilitated racial classification more than photographs, $\chi^{2}(1, n=41)=5.24, p=.022$; for younger children, there was no difference.

Compared to the person-description task, in which $56 \%$ of children used racial terms to describe the figures, in the categorization task, very few children $(15.6 \%)$ were guided by race of the figures. This difference may be contributed to by the more open nature of the description task, in which participants were encouraged to say anything that came into their minds about the figure presented. As noted, none of the children referred to figures' race as their first descriptor. Notwithstanding, it is surprising that not even the fact that the person-categorization task was presented after the person-description task had a sensitizing effect on children toward the skin color of the figures. In comparison to prior studies on spontaneous sorting of social material, the results of this study show a much lower proportion of classifications based on skin color. Thus, although children do notice race, they appear not to consider it important in categorizing social stimuli.

\subsection{Task 3: race labeling}

In this task, a response was considered correct when the child was capable of dividing the eight stimuli into two groups, one comprising the four Black figures and the other the four White figures.

Older children's performance was superior (82.9\%) to that of the younger participants (47.9\%), $\chi^{2}(1$, $n=89$ ) $=11.77, p=.001$, (Table 1 , row 3 ), both in the drawing and the photo conditions, although in the latter condition, the age difference was only marginally significant, $\chi^{2}(1, n=43)=9.92, p=.002$ and $\chi^{2}(1, n=46)=2.97, p=.085$, respectively, for DC and PC. These data suggest that older children (5-6 years) have a more stable social category of "race" than do younger children and that they recognize the label that is conventionally used to designate each group.

With regard to influence of the material, there were no significant differences in either age group. However, among DC participants, $90.5 \%$ of those who had mentioned race in the person-description task performed correctly on the race-labeling task, whereas only $45.5 \%$ of those who did not refer to race in the person-description task succeeded in this task. This trend was not observed among PC participants. Although few children spontaneously used race to organize the material in the categorization task, almost all those who did successfully solved the labeling-task in both conditions (DC, 90\%; PC, 100\%).

\subsection{Task 4: preference}

In this task, we coded as in-group preference the choice of a White figure, regardless of gender. As a whole, the results showed a high racial in-group preference (67 of the 90 children, $74.4 \%$ ) as well as a high same-gender preference ( 76 of the 90 children, $84.4 \%$ ).

Type of material had significant influence on older but not younger children. The latter showed similar levels of in-group preference for both types of stimuli. In contrast, older participants who worked with photos displayed more in-group preference than those who worked with drawings, a difference that was marginally significant, $\chi^{2}(1, n=42)=3.54, p=.060$ (Table 1 , row 4).

A binomial test was conducted to assess whether children's performance deviated from chance. The likelihood of choosing a same-race figure randomly was 50\% (since the targets were four black and four white children). Only PC participants performed above chance level, among both younger and older children $(73.1 \%, p=.029$ and $90.5 \%, p=.001$, respectively). 
Table 2

Means and standard deviations (in parentheses) of use of race by condition and age group.

\begin{tabular}{lll}
\hline & Drawing $(n=43)$ & Photographs $(n=47)$ \\
\hline Younger & $1.95(1.40)$ & $3.00(1.32)$ \\
Older & $3.61(1.43)$ & $3.75(0.85)$ \\
\hline
\end{tabular}

Note: maximum possible score is 6.00 .

\subsection{Task 5: drawing-photograph matching}

All participants worked with the same material in this task. Our interest was to determine whether having worked with photographic material or with drawings throughout the session would affect performance on this last task. Among the entire sample, $27 \%$ of participants failed to correctly match the drawing with the photo in either trial; $41.6 \%$ only performed correctly in one trial and $31.5 \%$ in both trials. The fifth row in Table 1 shows the percentage of children who correctly performed both matches, by age and condition.

Condition (PC or DC) and number of correct matches were associated. Participants who had worked throughout the session with photos more often had correct matches than those who had worked with drawings, $\chi^{2}(2, n=89)=6.17, p=.046$. Although the percentage of older children, both PC and DC, who correctly performed the two matches was higher than that of the younger children (Table 1 ), this difference was not statistically significant. In general, results for this task reveal the notable difficulty most children had in identifying the exact correspondence (that is, by gender and skin color) between a photo and a drawing in both trials-only about $25 \%$ and $38 \%$ of each age group, respectively, achieved this. This result suggests that children younger than 6 years of age still have trouble understanding correspondence between drawings and photographs. Virtually all children, in contrast, correctly matched the figures with respect to their gender. Mistakes this task were possibly attributable to the color of clothes attracting more attention than the color of skin.

\subsection{Overall scores}

An overall score was constructed for each participant based on the scores across the five tasks. Responses based on racial cues were coded as 1 , and the rest as 0 . Thus, the overall score ranged between 0 and 6 , because the matching task included two trials and both were coded.

These scores were analyzed with a two-way analysis of variance (ANOVA), with Age and Condition as the two factors. Results showed main effects of age, $F(1,87)=19.43, p<001, \eta_{p}^{2}=.20$, and Condition, $F(1,87)=4.61, p<.05, \eta_{p}^{2}=.05$; with no significant interaction. Thus, older children paid more attention to the racial attributes of the figures than did younger children, and PC participants attended to these attributes more than did DC participants (see Table 2).

\section{Discussion and conclusions}

The main goal of this study was to determine whether the type of material presented to children when assessing diverse aspects of their racial awareness affects their attention to racial cues. The results indicate that among preschool children, photographs and drawings do not elicit attention to the physical characteristics linked to race to the same extent. As a general tendency, we observed that the participants in the photo condition paid more attention to the figures' racial cues than did those in the drawing condition. That is, they mentioned the figures' skin color more frequently when describing them, they matched the stimuli better, and they showed a higher in-group bias than did the participants who worked with drawings. The exception to this tendency was found in the person-categorization tasks, which the drawing condition participants performed somewhat better than those from the photo condition. It is reasonable to expect that the realism of a photograph would evoke their referent better and provoke more emotional reactions than a drawing (MacDonald et al., 1996). Simplicity of a drawing, however, may favor the abstraction of regularities. Until now, this comparison had not been undertaken empirically within a single study. 
Our results suggest that the influence of type of material is far from simple or unidirectional and depends not only on the nature of the task but also on the participants' age. In some cases, type of material had a marked effect on the older children but a negligible effect on the younger ones, and in other cases, the opposite occurred. For example, photos elicited more favoritism or in-group preference than drawings, but only in the older children. In the person-description task, the photographic format led the younger children to mention the skin color of the figures more frequently, but it did not affect the older children who referred to race with the same high frequency for photos and for drawings.

The implication is that the measurement of racial awareness in small children may yield very diverse results depending on the material used. Thus, for example: Children's preferences assessed with drawings were about $65 \%$ in both age groups; among children who worked with photos, preferences were $70 \%$ and $90 \%$, respectively, in younger and older groups. If we only had the data from the drawing format, we would conclude that in-group favoritism is maintained at moderate levels in Spanish children from 3 to 6 years of age, with no developmental change over this age range. In contrast, if we only had the data from the photos, we would conclude that in-group favoritism is relatively elevated from early ages and continues to increase during the preschool years. In other tasks, in contrast, for example in person description, we found that the differences between younger and older children were notable when working with drawings, but not when working with photos. Recall that less than $20 \%$ of the younger children mentioned the color of skin of the drawings compared to almost $60 \%$ that did so when describing the photos. Thus, the data from the drawing format would lead us to conclude that Spanish preschoolers seem to be blind to racial cues until around the age of 5 years.

At this point, it is important to note that the results of our previous studies with Spanish preschoolers (Enesco et al., 1999; Giménez, 1999) are highly consistent with the present findings from the drawing format, but not from the photograph format. Only using drawings to assess the children's racial awareness and attitudes, it is quite possible that we underestimated the level of racial awareness of young Spaniards when we concluded that race is not salient for them before 5-6 years of age.

Therefore, at least in the case of our Spanish participants, the format can lead to different conclusions about the capacity being assessed. No less important is the fact that children of the ages studied here still have trouble establishing an exact correspondence between a photo and a drawing intended to represent the same referent, as seen in the results of the matching task. Recall that children never confused gender of the figures to be matched, but they attended more to the color of the clothes than to the skin color. This finding is difficult to interpret. On the one hand, it might simply indicate that the salience of race is moderate for young Spanish children and that it only becomes prominent in some circumstances, for example, when children are requested to "think" about their preferences and to make a choice. On the other hand, it might be contributed to by the fact that at these ages, children do not understand that the color of skin is constant. Preschool children still have trouble with the constancy of race (Giménez \& Harris, 2002; Hirschfeld, 1995), an aspect of racial understanding we did not address.

It is worthwhile to compare our findings to those from studies in other countries. For our participants, racial cues appear less relevant than they are for children in countries of multi-ethnic composition, including the UK (Katz \& Kofkin, 1997; Lam, Guerrero, Damree, \& Enesco, 2009; Rutland et al., 2005); the US (McGlothlin \& Killen, 2006; Ramsey, 1991); Australia (Nesdale, 1999) (see Enesco, Guerrero, Callejas, \& Solbes, 2008, for a discussion of these differences). Perhaps the most notable difference between these findings and our own is that one half of our younger participants did not even recognize the conventional labels of Black and White, a finding consistent with previous studies with 3- and 4-year-old Spanish children (Giménez, 1999; Guerrero \& Enesco, 2008), who seem to ignore racial terms and to sometimes act as if skin color is invisible. The results of the present study pose a new issue in addition to the already numerous ones in the study of prejudice: In contrast to historical and sociodemographic variables, the material with which one works can be easily controlled. Future research should determine how the nature of the material affects performance and, consequently, take this into account when designing new studies. The relevance of this issue extends beyond basic research. If photographs activate evaluative and attitudinal components, researchers should take this into account when designing intervention programs, selecting the most adequate format for their goals. For example, photographs may be more useful than drawings as a complementary tool for decategorization strategies (Cameron \& Rutland, 2008), where the basic assumption is that prejudices are likely 
to decrease as long as our perception of others is based on their personal characteristics and not on them as members of a distinct group. In multi-ethnic schools, photographic material might combine pictures of unknown children (as is customary in most previous research) with pictures of school peers from different ethnic and national backgrounds, whose individual characteristics can be used to direct classmates' attention to the abilities, preferences, or personality traits of any particular peer.

Photos may be likely to facilitate these socio-cognitive processes. Yet, they will never replace the rich experience of personal contact to enhance children's comprehension of the fact that we share many common characteristics with members from different groups.

\section{References}

Aboud, F. E. (1987). The development of ethnic self-identification and attitudes. In J. Phinney, \& M. Rotheram (Eds.), Children's ethnic socialisation: Pluralism and development (pp. 32-55). Newbury Park, CA: Sage.

Aboud, F. E. (1988). Children and prejudice. Oxford: Blackwell.

Aboud, F. E., \& Amato, M. (2001). Developmental and socialization influences on inter-group bias. In R. Brown, \& S. Gaerther (Eds.), Blackwell handbook of social psychology: intergroup processes (pp. 65-85). Oxford: Blackwell.

Callaghan, T. C. (1999). Early understanding and production of graphic symbols. Child Development, 70, 1314-1324.

Callaghan, T. C. (2000). Factors affecting graphic symbol understanding in the third year: Language, similarity and iconicity. Cognitive Development, 15, 207-236.

Callaghan, T. C., \& Rankin, M. (2002). Emergence of graphic symbol functioning and the question of domain specificity: A longitudinal training study. Child Development, 73, 359-376.

Cameron, L., \& Rutland, A. (2008). An integrative approach to changing children's intergroup attitudes. In S. Levy, \& M. Killen (Eds.), Intergroup attitudes and relations in childhood through adulthood. New York: Oxford University Press.

Clark, K. B., \& Clark, M. K. (1947). Racial identification and preference in Negro children. In T. Newcombe, \& E. Hartley (Eds.), Readings in social psychology (pp. 169-178). New York: Holt.

Cramer, P., \& Steinwert, T. (1998). Thin is good, fat is bad: How early does it begin? Journal Applied Developmental Psychology, 19, 429-451.

Cunningham, J. G., \& Odom, R. D. (1986). Differential salience of facial features in children's perception of affective expression. Child Development, 57, 136-142.

Davey, A. G. (1983). Learning to be prejudiced: Growing up in multi-ethnic Britain. London: Edward Arnold.

DeLoache, J. S. (1987). Rapid change in the symbolic functioning of very young children. Science, 238, 1556-1557.

DeLoache, J. S. (2000). Dual representation and young children's use of scale models. Child Development, 71, 329-338.

DeLoache, J. S. (2002). The symbol-mindedness of young children. In W. Hartup, \& R. Weinberg (Eds.), The Minnesota Symposium on Child Psychology, Vol. 32: In Celebration of the 75th Anniversary of the Institute of Child Development (pp. 73-101). Mahwah, NJ: Erlbaum.

Doyle, A. B., \& Aboud, F. E. (1995). A longitudinal study of white children's racial prejudice as a social-cognitive development. Merrill-Palmer Quarterly, 41, 209-228.

Enesco, I., del Olmo, Giménez, M., \& Paradela, I. (1998). El desarrollo de las ideas y actitudes étnico-raciales: una revisión crítica [The development of ethnic-racial ideas and attitudes: A critical review]. Estudios de Psicología, 59, 87-104.

Enesco, I., Navarro, A., Giménez, M., \& del Olmo, C. (1999). Génesis de la conciencia racial: Un estudio sobre identificación \& actitudes hacia el color de piel en niños de tres a once años [Genesis of racial awareness: A study of identification and attitudes toward skin color in children from 3 to 11 years]. Estudios de Psicología, 3-20, 63-64.

Enesco, I., Guerrero, S., Callejas, C., \& Solbes, I. (2008). Intergoup attitudes and social reasoning among majority and minority group children living in Spain. In S. Levy, \& M. Killen (Eds.), Intergroup attitudes and relations in childhood through adulthood. New York: Oxford University Press.

Giménez, M. (1999). El desarrollo de la conciencia racial: Actitudes e ideas implícitas en niños de tres a seis años [The developmentl of racial awareness: Attitudes and implicit ideas in children from 3 to 6 yeras]. Doctoral dissertation. Spain: Universidad Complutense de Madrid.

Giménez, M., \& Harris, P. (2002). Understanding constraints on inheritance: Evidence for biological thinking in early childhood. British Journal of Developmental Psychology, 20, 307-324.

Guerrero, S., \& Enesco, I. (2008). The development of racial awareness. A developmental study with Spanish children from 3 to 5 years. Saarbrücken, Germany: Verlag Dr. Müller.

Guerrero, S., Enesco, I., \& Lam, V. (submitted for publication). Racial awareness, cognitive performance and affect: A study with preschool children.

Hirschfeld, L. (1995). Do children have a theory of race? Cognition, 54, 209-252.

I.N.E., National Institute of Statistic (2008). http://www.ine.es/en/welcome_en.htm.

Katz, P. A., \& Kofkin, J. A. (1997). Race, gender and young children. In S. Luthar, J. Burack, D. Cicchetti, \& J. Weisz (Eds.), Developmental perspectives on risk and pathology (pp. 51-74). New York: Cambridge University Press.

Lam, V., Guerrero, S., Damree, N., \& Enesco, I. (submitted for publication). Young children's racial cognition and affect in a multiracial context.

MacDonald, P. M., Kirkpatrick, S. W., \& Sullivan, L. A. (1996). Schematic drawings of facial expressions for emotion recognition and interpretation by preschool-aged children. Genetic, Social and General Psychology Monographs, 122(4), 373-388.

Madey, S. F., \& Ondrus, S. A. (1999). Illusory correlations in perceptions of obese and hypertensive patients' non-cooperative behaviors. Journal of Health Psychology, 2, 555-559.

Madole, K. L., \& Oakes, L. M. (1999). Making sense of infant categorization: Stable processes and changing representations. Developmental Review, 19, 263-296.

Marsh, A. (1970). Awareness of racial differences in West African and British children. Race, 11, 289-302. 
McGlothlin, H., \& Killen, M. (2006). Intergroup attitudes of European American children attending ethnically homogeneous schools. Child Development, 77, 1375-1386.

Milner, D. (1983). Children and race: Ten years on. London: Ward Lock Educational.

Nesdale, D. (2002). Social identity and ethnic prejudice in children. In D. Gabb, \& T. Miletic (Eds.), Culture, race and community: Making it work in the new millennium. Melbourne, Australia: Victorian Transcultural Psychiatry Unit. http://www.vtpu.org.au/docs/crc/drewnesdale.pdf

Nesdale, D. (1999). Developmental changes in children's ethnic preferences and social cognitions. Journal of Applied Developmental Psychology, 20, 501-519.

Powlishta, K. K., Serbin, L. A., Doyle, A. B., \& White, D. R. (1994). Gender, ethnic, and body type biases: The generality of prejudice in childhood. Developmental Psychology, 30, 526-536.

Rakoczy, H., Tomasello, M., \& Striano, T. (2005). How children turn objects into symbols: A cultural learning account. In L. Namy (Ed.), Symbol use and symbol representation (pp. 67-97). Mahwah, NJ: Erlbaum.

Ramsey, P. G. (1991). The salience of race in young children growing up in an all-White community. Journal of Educational Psychology, 83, 28-34.

Ramsey, P. G., \& Myers, L. C. (1990). Salience of race in young children's cognitive, affective, and behavioural responses to social environments. Journal of Applied Developmental Psychology, 11, 49-67.

Rutland, A., Cameron, L., Bennett, L., \& Ferrell, J. (2005). Interracial contact and racial constancy: A multi-site study of racial intergroup bias in 3-5-year old Anglo-British children. Journal of Applied Developmental Psychology, 25, 699-713.

Semaj, L. T. (1981). The development of racial-classification abilities. Journal of Negro Education, 50, 41-48.

Sullivan, L. A., Kirkpatrick, S. W., \& MacDonald, P. M. (1995). Interpretations of facial expressions of emotion by sexually abused and non-abused girls. Journal of Child Sexual Abuse, 4, 45-61.

Van Parys, M. M. (1981). Preschoolers in society: Use of social roles of sex, age, and race for self and others by Black and White children. In Paper presented in the biennial meeting of the international society for the study of behavioral development Toronto,

Williams, J. E., \& Morland, J. K. (1976). Race color and the young child. Chapel Hill, NC: University of North Carolina Press. 